University of Nebraska - Lincoln

DigitalCommons@University of Nebraska - Lincoln

P. F. (Paul Frazer) Williams Publications

Electrical \& Computer Engineering, Department

June 1980

\title{
New Infrared Laser Lines in Argon, Krypton, and Xenon
}

E. L. Brown

Texas Technical University, Lubbock, TX

M. A. Gundersen

Texas Technical University, Lubbock, TX

P. F. Williams

University of Nebraska - Lincoln, pfw@moi.unl.edu

Follow this and additional works at: https://digitalcommons.unl.edu/elecengwilliams

Part of the Electrical and Computer Engineering Commons

Brown, E. L.; Gundersen, M. A.; and Williams, P. F., "New Infrared Laser Lines in Argon, Krypton, and Xenon" (1980). P. F. (Paul Frazer) Williams Publications. 8.

https://digitalcommons.unl.edu/elecengwilliams/8

This Article is brought to you for free and open access by the Electrical \& Computer Engineering, Department of at DigitalCommons@University of Nebraska - Lincoln. It has been accepted for inclusion in P. F. (Paul Frazer) Williams Publications by an authorized administrator of DigitalCommons@University of Nebraska - Lincoln. 


\section{Notes and Lines}

\section{New Infrared Laser Lines in Argon, Krypton, and Xenon}

\section{E. L. BROWN, M. A. GUNDERSEN, AND P. F. WILLIAMS}

Abstract-Fourteen new infrared laser transitions in $\mathrm{Ar}, \mathrm{Kr}$, and $\mathrm{Xe}$ ranging from 3.725 to $17.233 \mu \mathrm{m}$ are reported. All of the $\mathrm{Kr}$ laser transitions and all but one of the $\mathrm{Ar}$ and Xe transitions have upper levels in the $s$ or $d$ state: the majority of the transitions satisfy the condition $\Delta K=\Delta J$. Identification of a previously observed, unidentified laser line at $5.804 \mu \mathrm{m}$ in $\mathrm{Ar}$ is given.

Nobel gas lasers are of interest for many applications because they exhibit long-term frequency stability, a wide range of wavelengths, and useful power levels. In pulsed systems high peak power has been observed over a wide range of wavelengths [1], [2], [6]. Because of the interest in new infrared (IR) lasers and the lack of published data in the IR under these conditions, a survey of $\mathrm{Ar}, \mathrm{Kr}$, and Xe was conducted. A $3 \mathrm{~m}$ longitudinal discharge laser capable of operation at pressures down to $5 \mu$ and at current densities up to approximately 175 $\mathrm{A} / \mathrm{cm}^{2}$ was used. Nineteen new transitions were observed, ranging in wavelength from 3.631 to $17.233 \mu$. All but one of the transitions were identified as neutral species, although it had been anticipated that new transitions at high current densities would be ionized species. The strongest transitions were observed in $\mathrm{Kr}$ at $4.15 \mu$ and $\mathrm{Xe}$ at 7.8 and $8.4 \mu$.

A longitudinal discharge laser was used for this work [2]. The plasma tube was made from Pyrex tubing with an inside diameter of $19 \mathrm{~mm}$ and the electrical discharge was divided into two $1.5 \mathrm{~m}$ sections for better stability. Each end of the laser contained an indium cathode [3] and the center electrodes were grounded anodes constructed from molybdenum. The ends of the plasma tube were sealed with $\mathrm{KCl}$ Brewster windows which passed radiation with wavelengths from 0.1 to $17 \mu \mathrm{m}$, although the optical quality of the windows hindered oscillation at wavelengths below roughly $1 \mu \mathrm{m}$. The optical cavity consisted of a $20 \mathrm{~m}$ radius mirror and a flat containing a $3 \mathrm{~mm}$ diameter pinhole to couple out radiation. Both mirror surfaces were silver overcoated with thorium oxyfluoride. 0.2 $\mu \mathrm{F}$ capacitors were charged to a voltage of $16-20 \mathrm{kV}$ and discharged through the plasma tube with a spark gap. The current rise time was roughly $1 \mu \mathrm{s}$, and peak current densities up to $176 \mathrm{~A} / \mathrm{cm}^{2}$ were obtained.

Rough wavelength measurements were made with various filters and more accurate measurements were made using a half meter double spectrometer with 600 grooves/mm gratings blazed at $16 \mu \mathrm{m}$. The laser radiation was detected by a $\mathrm{HgCdTe}$ detector with sensitivity extending to $18 \mu \mathrm{m}$. With this apparatus, measurements accurate to $0.003 \mu \mathrm{m}$ could be made between 2 and $18 \mu \mathrm{m}$.

\section{EXPERIMENTAL RESULTS}

Table I gives a listing of the new laser transitions observed in each of the noble gases [7]. The light pulse occurred typically $100 \mathrm{~ns}$ after the beginning of the current pulse and had a pulse length of 200-400 ns depending on the pressure and gas used.

In order to make term assignments, a computer program was

Manuscript received November 2,1979. This work was supported by the Department of Energy.

The authors are with the Department of Electrical Engineering, Texas Technical University, Lubbock, TX 79409.
TABLE I

INFRARED Transitions OBSERVED IN Ar, Kr, AND Xe LASERS

\begin{tabular}{|c|c|c|c|c|c|}
\hline & $\begin{array}{c}\text { Measured } \\
\text { Wavelength } \\
\text { (Microns) } \\
\pm 0.003 \\
\end{array}$ & $\begin{array}{l}\text { Calculated } \\
\text { Wavelength } \\
4\end{array}$ & $\begin{array}{c}\text { Term } \\
\text { Assignment }\end{array}$ & $\begin{array}{l}\text { Relative } \\
\text { Line } \\
\text { strength }\end{array}$ & $\begin{array}{l}\text { Pressure } \\
\text { (Microns) }\end{array}$ \\
\hline \multirow{5}{*}{ Ar } & $5.804^{\mathrm{b}}$ & 5.8037 & $4 \mathrm{~d}\left[1 \frac{1}{2}\right]_{2}-5 \mathrm{p}\left[1^{\frac{1}{2}}\right]_{2}$ & $w$ & 20 \\
\hline & 6.812 & 6.8129 & $4 a\left[\frac{1}{2}\right]_{1}-5 p\left[1 \frac{1}{2}\right]_{2}$ & $w$ & 250 \\
\hline & 7.956 & 7.955 & $5 d\left[1 \frac{1}{2}\right]_{1}-6 p\left[1 \frac{1}{2}\right]_{1}$ & $\mathrm{~m}$ & 20 \\
\hline & 11.042 & 11.0415 & $7 p\left[\frac{1}{2}\right]_{0}-7 s[1 s]_{1}$ & w & \\
\hline & 13.475 & & & $\mathrm{~m}$ & 250 \\
\hline \multirow{5}{*}{$\underline{\mathrm{Kr}}$} & 8.115 & 8. 1151 & $8 s\left[1 \frac{1}{3}\right]_{1}-7 p\left[2 \frac{1}{2}\right]_{2}$ & $w$ & 50 \\
\hline & 9.637 & 9.639 & $6 \mathrm{~d}\left[1 \frac{1}{2}\right]_{1}-7 \mathrm{p}\left[1 \frac{1}{2}\right]_{1}$ & $w$ & 50 \\
\hline & 10.937 & 10.9337 & $5 \mathrm{~d}[\mathrm{k} /]_{1}-6 \mathrm{p}\left[\frac{\mathrm{k}}{2}\right]_{1}$ & $\mathrm{~m}$ & 50 \\
\hline & 17.070 & 17.0709 & $4 d^{\prime}\left[2 \frac{1}{2}\right]_{3}-6 \mathrm{p}\left[2 \frac{1}{2}\right]_{3}$ & $\mathrm{~m}$ & 50 \\
\hline & 17.233 & 17.2328 & $4 d^{\prime}\left[2 \frac{1}{2}\right]_{3}-6 p\left[2 \frac{1}{2}\right]_{2}$ & $\mathrm{~m}$ & 50 \\
\hline \multirow{5}{*}{$\underline{\mathrm{Xe}}$} & 3.725 & 3.7265 & $5 d^{\prime}\left[2 \frac{1}{2}\right]_{2}-7 p\left[2 \varliminf_{3}\right.$ & w & 150 \\
\hline & 7.767 & 7.7665 & 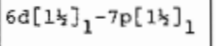 & $\mathbf{s}$ & 150 \\
\hline & 7.782 & 7.7813 & $5 d^{\prime} \cdot\left[1 \frac{1}{2}\right]_{1}-8 p[1 \lesseqgtr]_{1}$ & $\mathbf{s}$ & 150 \\
\hline & 8.404 & 3.4042 & $6 \mathrm{~d}\left[1 \mathrm{~s}_{2}\right]_{1}-7 \mathrm{p}[\mathrm{s}]_{0}$ & s & 150 \\
\hline & 11.582 & 11.5821 & $90\left[\frac{1}{2}\right]_{0}-9 s\left[1 \frac{1}{2}\right]_{2}$ & $\mathrm{~m}$ & 20 \\
\hline
\end{tabular}

a pulse energies for the strong lines were of the order .1-1uJ.

b reported in Ref. 5 .

written to calculate the energy differences between known energy levels [4], [7] satisfying the $j l$ coupling selection rules $(\Delta \mathrm{l}=+1$ and $\Delta J=0, \pm 1)$. The measured wavelengths were then compared to those calculated. The procedure was followed not only for neutral species but also for the known ionized species. All but one of the observed wavelengths were identified with neutral transitions. No term assignment could be given to the $13.475 \mu \mathrm{m}$ line observed in $\mathrm{Ar}$, even after including all the know ionized transitions.

Term assignments obtained in this manner are given in Table I using Racah $j l$ notation with the upper levels given first. The energy levels are denoted by $n l[K] j$ with an unprimed 1 value indicating a ${ }^{2} P_{3 / 2}$ core state and a primed 1 value indicating a ${ }^{2} P_{1 / 2}$ core. Transitions appear to occur in groups sharing initial levels.

A term assignment for the previously observed but unidentified $5.804 \mu \mathrm{m}$ line in $\operatorname{Ar}$ [5] is given in the table. Two $d^{\prime}-p$ transitions in $\mathrm{Kr}$ and two transitions in $\mathrm{Xe}$ have been listed in the Table that involve a change in the parent core configuration. Although these transitions are forbidden by selection rules for $j l$ coupling, similar transitions have been previously reported [1]. In addition, because the density of states increases for the high lying levels, for an equal distribution of electron energies these levels have a lower probability of attaining a sufficient population to produce an inversion. Therefore, transitions with upper levels above about $8 s, 7 p, 6 d$ are neglected.

All of the $\mathrm{Kr}$ transitions observed and all but one of the Ar and Xe transitions have upper levels in the $s$ or $d$ state. Previous observations [1] suggest that inversion between the $s-p$ and $d-p$ states can be produced by electron impact excitation. When the primary excitation mechanism is due to electron impact with electron energies well above the threshold, excita- 
tion can occur predominately from the ground state $p$-shell to $s$ and $d$ states that are strongly connected to the ground states by optical transitions. From a calculation of line strengths, it may be shown that the strongest transitions satisfy $\Delta K=\Delta J$ [2]. All of the transitions in Xe, all but one transition in Ar, and half of the transitions in $\mathrm{Kr}$ satisfy this condition.

\section{REFERENCES}

[1] W. L. Faust, R. A. McFarlane, C. K. N. Patel, and C. G. B. Garrett, "Noble gas optical master lines at wavelengths between $2 \mu$ and 35 ,", Phys. Rev., vol. 133, pp. A1476-A1486, Mar. 1964.

[2] C. D. Harper and M. Gundersen, "Construction of a high power xenon ion laser," Rev. Sci. Instrum., vol. 45, pp. 400-402, Feb. 1974.

[3] W. W. Simmons and R. S. Witte, "New cold cathode for pulsed ion lasers," IEEE J. Quantum Electron., vol. QE-6, pp. 648-649, Oct. 1970.

[4] Charlotte E. Moore, "Atomic energy levels," Nat. Stand. Ref. Data Ser., Nat. Bur. Stands., Dec. 1971.

[5] O. R. Wood, E. G. Burkhardt, M. A. Pollack, and T. J. Bridges, "High-pressure laser action in 13 gases with transverse excitation," Appl. Phys. Lett., vol. 18, pp. 261-264, Mar. 1971.

[6] G. J. Linford, "High-gain neutral laser lines in pulsed noble-gas discharges," IEEE J. Quantum Electron., vol. QE-8, pp. 477-482, June 1972.

[7] E. L. Brown, M.S. thesis, Texas Technical University, Lubbock, TX, unpublished. 